\title{
Editorial: A Vision for the Future of the Journal
}

\author{
Pinnaduwa H. S. W. Kulatilake
}

Accepted: 22 November 2021 / Published online: 24 December 2021

(C) The Author(s), under exclusive licence to Springer Nature Switzerland AG 2021

In October 2021, I was delighted to accept the invitation from the publishing Editor of the Journal, Ms. Petra van Steenbergen and SPRINGER NATURE to serve as an Editor-in-Chief for the Geotechnical and Geological Engineering Journal. I would like to thank Ms. van Steenbergen and the current Editors-in-Chief of the Journal, Professors David G. Toll and James Hanson, for the welcomes they extended to me.

Since 1983, the journal has been publishing articles on a diverse spectrum of geoengineering topics covering soil mechanics and soil engineering, rock mechanics and rock engineering, and engineering geology for the civil geotechnical, mining, and geological engineering fields. Going forward, the journal intends to expand the coverage on almost any topic in the aforementioned disciplines, aiming to achieve a balance between theory and practice. We plan to cover experimental, theoretical, analytical, numerical, statistical, probabilistic, and artificial intelligence research, as well as applications to the real world. In addition to individual research or state-ofthe-art articles, the journal aims to publish several Special Issues to build collections of papers dedicated

P. H. S. W. Kulatilake ( $\square)$

Ganzhou, Jiangxi, China

P. H. S. W. Kulatilake

Tucson, AZ, USA

e-mail: kulatila@u.arizona.edu to the synthesis of important and emerging popular topics in the soil and rock engineering and geological engineering disciplines. I would like to cordially invite researchers to propose special issues on topics that they have the interest to explore their ideas further.

In 2022, the journal would like to take necessary action to prepare the journal for a successful application to get included in the SCI category among the geotechnical engineering journals. To achieve this, the journal plans to improve the number of citations received per published paper through more highquality individual as well as special issue publications. Due to the popularity of the journal, the number of high-quality manuscripts submitted to the journal has been increasing lately. Therefore, starting in 2022, the publishing frequency of the journal will change from 8 to 12 issues.

The journal is currently implementing several steps to reduce the turnaround time between the submission and acceptance/rejection of the manuscripts. Steps include both accelerating the acceptance/declination response on the review invitations, and emphasis on timely completion of reviews if accepted. Reviewers' support on this matter is greatly appreciated. Regarding English grammar refinement, if the authors doubt the English level of the manuscript, they are advised to get the manuscript revised by a native English writer before submitting it to the journal website.

With the help of the dedicated and efficient publishing staff and an eminent international editorial 
board listed on the journal's website, we are fully focused on making Geotechnical and Geological Engineering one of the top journals in the Geotechnical Engineering field, providing articles with a good balance between theory and practice. We cordially invite potential authors from all over the world to submit their high-quality contributions to the journal to achieve this goal and look forward to growing the journal as we move into 2022 .

Distinguished Professor Pinnaduwa H.S.W. Kulatilake, Ph.D., PE (Civil Engg.), F.ASCE, M.SME, M.Engg. Geology

Editor-in-Chief

Geotechnical and Geological Engineering

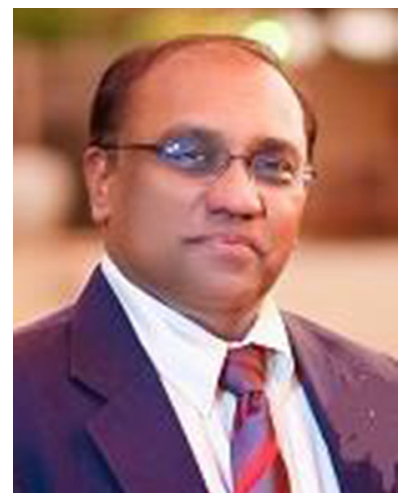

Pinnaduwa H.S.W. Kulatilake is an Academic Director and a Distinguished Professor of Rock Mechanics and Rock Engineering at the Jiangxi University of Science and Technology, China, and a Professor Emeritus at the University of Arizona. He has over 40 years of experience in rock mechanics and rock engineering and applications of probabilistic, statistical, and numerical methods to geo and mining engineering. Prof. Kulatilake's papers have received over 6000 citations with an i10 index of 100 and an $\mathrm{H}$ index of 42 . He has delivered over 40 keynote lectures, 50 other invited lectures and taught 56 short courses throughout the world. He has won numerous prestigious awards and served over 20 years as the main examiner for the geological engineering professional exam conducted by the Arizona State Board of Technical Registration.

Publisher's Note Springer Nature remains neutral with regard to jurisdictional claims in published maps and institutional affiliations. 